\title{
Robotic mitral valve surgery: a review and tips for safely negotiating the learning curve
}

\author{
Caroline Toolan, Kenneth Palmer, Omar Al-Rawi, Tim Ridgway, Paul Modi
}

The Liverpool Heart \& Chest Hospital, Liverpool, UK

Contributions: (I) Conception and design: C Toolan, P Modi; (II) Administrative support: None; (III) Provision of study materials or patients: None; (IV) Collection and assembly of data: C Toolan; (V) Data analysis and interpretation: C Toolan, P Modi; (VI) Manuscript writing: All authors; (VII) Final approval of manuscript: All authors.

Correspondence to: Mr. Paul Modi, MD, FRCS. Consultant Cardiac Surgeon, Liverpool Heart \& Chest Hospital, Thomas Drive, Liverpool L14 3PE, UK. Email: paul.modi@lhch.nhs.uk.

\begin{abstract}
Totally endoscopic robotic mitral valve repair represents the least invasive surgical therapy for mitral valve disease. Comparative results for robotic mitral valve surgery against sternotomy are impressive, repeatedly demonstrating shorter hospital stay, faster return to normal activities, less morbidity and equivalent mortality and mid-term durability. We lack data comparing robotic approaches to totally endoscopic minimally invasive mitral valve surgery using $3 \mathrm{D}$ vision platforms. In this review, we explore the advantages and disadvantages of robotic mitral valve surgery and share technical tips that we have learned to help teams embarking on their robotic journey. We consider factors necessary for the successful implementation of a robotic programme including the importance of training a dedicated team, with the common goal to avoid any compromise in either patient safety or repair quality during the learning curve. As experience grows with robotic techniques and more cardiac surgeons become proficient with this innovative technology, the volume of robotic cardiac procedures around the world will increase helped by the introduction of new robotic systems and patient demand. Well informed patients will increasingly seek out the opportunity of robotic valve reconstruction in reference centres in the hands of a few highly experienced robotic surgeons.
\end{abstract}

Keywords: Mitral valve; robotics; minimally invasive; outcomes

Submitted Apr 28, 2020. Accepted for publication Oct 12, 2020.

doi: $10.21037 /$ jtd-20-1790

View this article at: http://dx.doi.org/10.21037/jtd-20-1790

\section{Introduction}

Mitral valve surgery has a long history of innovation, being at the leading edge of development of minimally invasive cardiac surgical (MICS) techniques for over two decades now. Recognition of the significant advantages of minimizing surgical trauma by reducing incision size and eliminating rib-spreading has resulted in a substantial increase in the number of minimally invasive cardiac surgical procedures being undertaken internationally, such that $54 \%$ of isolated mitral valve disease in Germany is now performed using minimally invasive (predominantly non-robotic) techniques (1). The benefits of MICS include less pain, blood loss, shorter hospital stays, faster return to normal activities and improved cosmesis when compared to conventional sternotomy surgery. This is at the expense of consistently longer operative times that reach parity with increasing experience (2-5). Advances in MICS have been facilitated by improvements in surgical techniques (e.g., Gore-Tex loops), instrumentation (shafted instruments), perfusion technology (thin-walled reinforced cannulae) and vision platforms (3D video stacks). Improvements have ensured that minimally invasive procedures are as effective and durable as conventional surgery (6). 

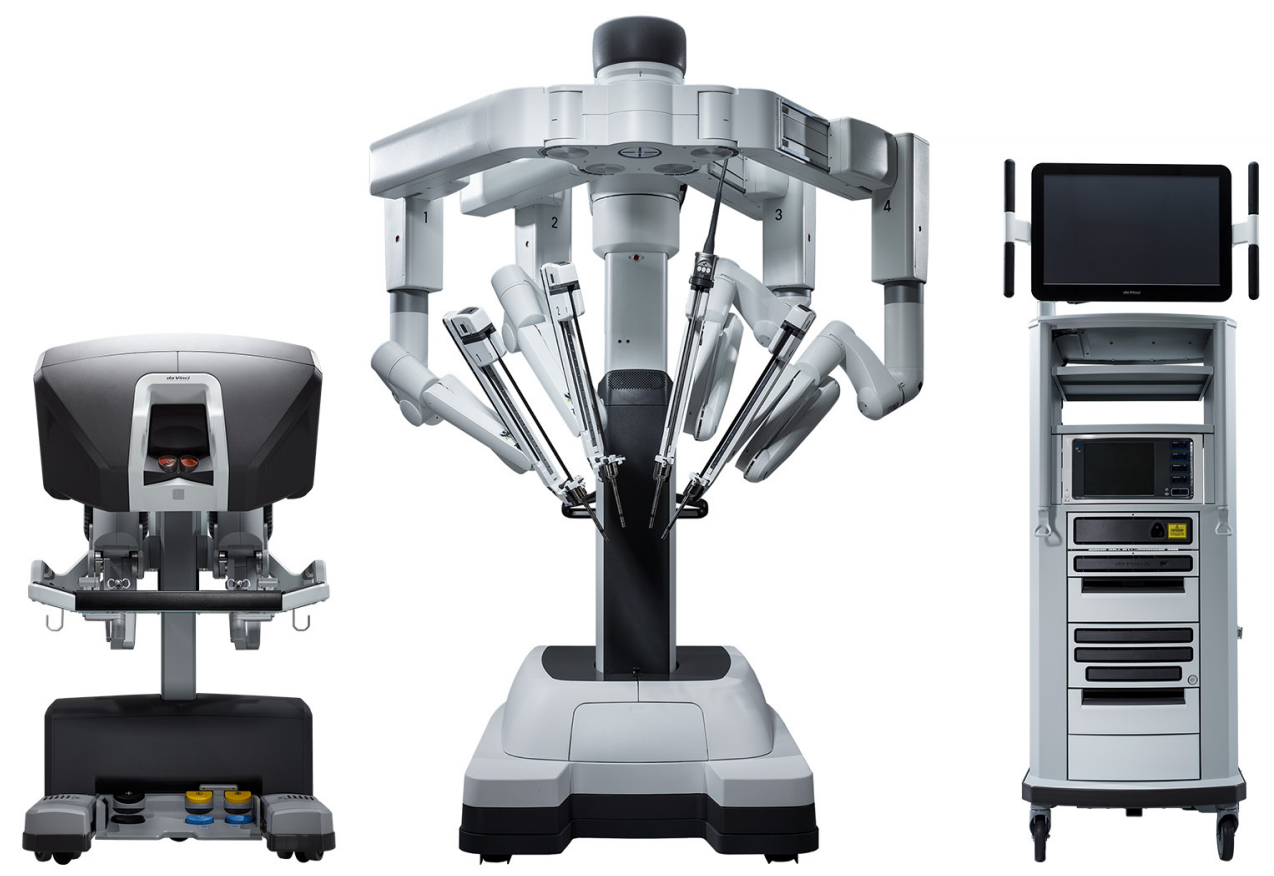

Figure 1 The da Vinci Xi (reproduced with permission from Intuitive Surgical).

\section{Potential advantages of robotic surgery over mini-mitral surgery}

There are several disadvantages of video-assisted mitral valve surgery. Although the minithoracotomy skin incision is small, usually $4-6 \mathrm{~cm}$ in most surgeons' hands, the intercostal incision is larger, probably $8-10 \mathrm{~cm}$. Undercutting of the incision allows the ribs to spread wider with just a soft tissue retractor permitting surgery using direct vision which is more familiar and expeditious. Relatively few surgeons performing mini mitral surgery have mastered a totally endoscopic procedure. Robotic surgery using the da Vinci system (Intuitive Surgical, CA, USA) requires the surgeon to work completely endoscopically as the console is remote from the patient. A truly minimally invasive approach where the largest port incision is $20 \mathrm{~mm}$ or smaller can therefore be achieved (Figures 1,2). We believe the faster recovery observed with robotic surgery when compared to mini-mitral surgery at our institution is probably related to these factors, as well as the remote centering of the da Vinci arms ensuring that minimal pressure is placed on the intercostal bundles. Whether any advantage in operative durations or patient benefit can be demonstrated in comparison to totally endoscopic mini mitral surgery using $3 \mathrm{D}$ vision platforms remains to be clarified.

Robotic surgery also provides a solution to the limited dexterity of endoscopic instrumentation (only 4 degrees of freedom combined with the fulcrum effect). This is frequently challenging for many cardiac surgical procedures, and the loss of depth perception if $2 \mathrm{D}$ video monitors are used only further compounds operative difficulty. The robotic console facilitates surgical virtual immersion into the operative field through $3 \mathrm{D}$-HD imaging, placing the surgeon inside the left atrium with a line of vision parallel to the flow of blood through the mitral valve (Figure 3). Finger and wrist movements are registered through sensors and translated into motion-scaled tremor-free movements avoiding both the fulcrum effect and the instrument shaft shear forces common to long-shafted endoscopic instruments. Wrist-like articulations at the ends of microinstruments bring the pivoting action of the instrument to the plane of the operative field, improving dexterity in tight spaces and allowing truly ambidextrous suture placement.

\section{Early development}

Many of the pioneers of video-assisted or endoscopic mitral valve surgery were also early adopters of robotic technology, with Carpentier, Mohr, Chitwood and Murphy 


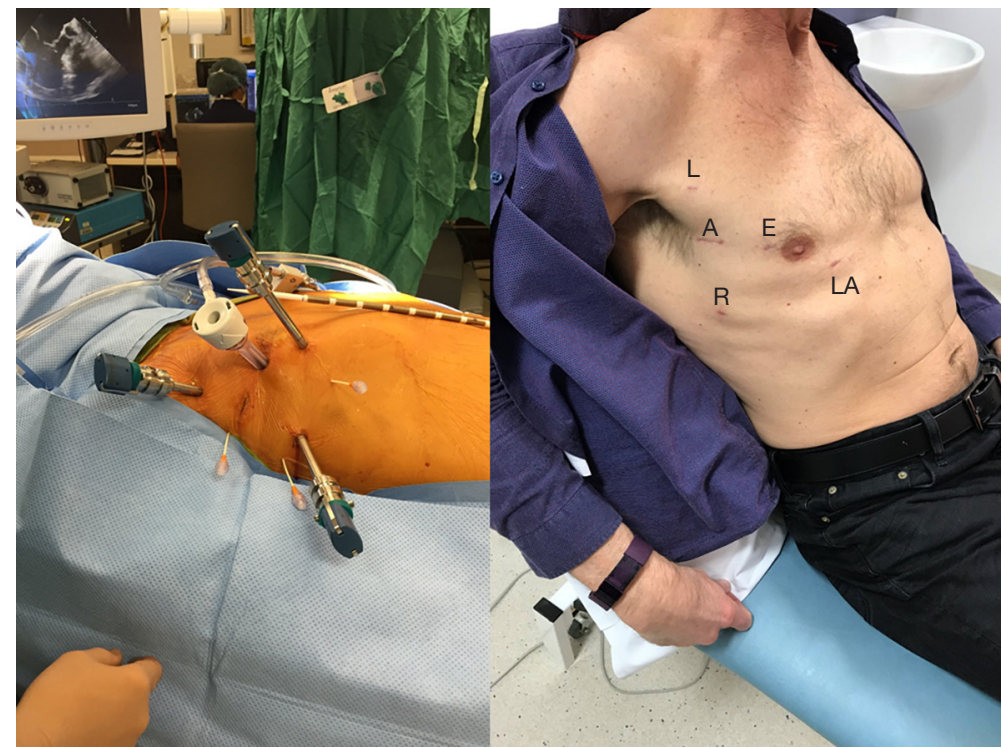

Figure 2 The LEAR Technique (Lateral Endoscopic Approach for Robotics). A, access port; E, endoscope port; L, left arm port; LA, left atrial retractor port; $\mathrm{R}$, right arm port.

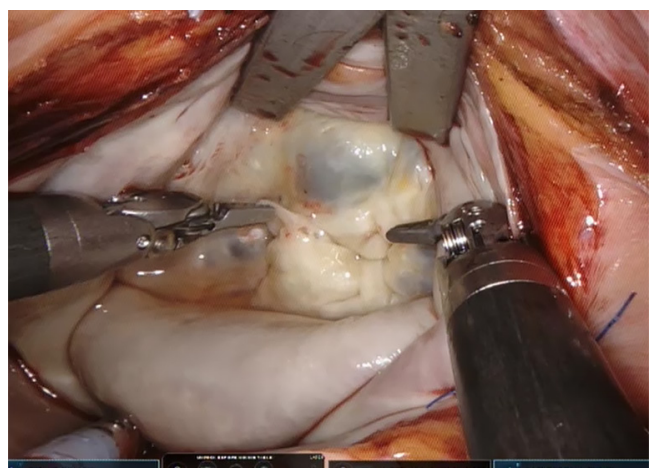

Figure 3 The operative view with the da Vinci.

leading the way (7-9). The first robotic mitral valve repair was performed in May 1998 by Carpentier using an early prototype of the da Vinci articulated intracardiac "wrist" robotic device (7). A week later, Mohr performed the first coronary anastomosis and repaired five mitral valves with the device (8). Grossi et al. (10) of New York University partially repaired a mitral valve using the Zeus ${ }^{\mathrm{TM}}$ system (Computer Motion Inc., CA, USA) but no annuloplasty ring was inserted. Four days later, in May 2000, Chitwood performed the first complete da Vinci mitral repair in North America. Two Food and Drug Administration (FDA) trials subsequently led to approval in November 2002 of the da Vinci system for mitral valve surgery $(11,12)$.
Since then, the US has seen the greatest uptake of robotic cardiac surgery, probably due to the competitive nature of their healthcare system. Case numbers plateaued at approximately 1,700 robotic mitral valve procedures per year from 2009 to 2015 (13). However, robotic surgery in Europe is making a resurgence, with a steep increase in the annual number of cases as new centres take up this pioneering technology. In this review, we will evaluate the current evidence for robotic mitral valve repair.

\section{Operative outcomes}

One of the key challenges when introducing any less invasive technique has been the ability to demonstrate at least equal if not better results when compared to a gold standard of median sternotomy. Randomised controlled trials comparing operative techniques face tough hurdles. For example, appropriate blinding of patients and agreement of surgeons to use sternotomy in institutions with well-established robotic programmes and favorable outcomes. When well-informed patients are faced with the $50 \%$ possibility of being randomised to a sternotomy in one institution, they are likely to search for their desired treatment elsewhere. As a result, evaluation of robotic mitral valve surgery is based largely on single centre experiences supplemented by large database analyses with propensity matching. 


\section{Mortality}

Patients entered into robotic programmes have certainly been more selected than those undergoing sternotomy. Avoidance of retrograde femoral arterial perfusion in patients with significant aortovascular disease and the exclusion of patients with severe mitral annular calcification has contributed to robotic cohorts which are younger and with fewer co-morbidities than sternotomy groups $(14,15)$. Unmatched comparisons have therefore not unsurprisingly shown a lower mortality for robotic mitral valve patients, which fails to retain significance when matched comparisons are made (14). In a propensity score matched analysis of 631 pairs of patients, Paul et al. (14) found no significant difference for in-hospital mortality, complications, or composite outcomes in unadjusted or multivariable analyses, between patients undergoing robotic-assisted and non-robotic mitral valve repair. However, what remains overwhelmingly consistent is an operative mortality with robotic mitral valve repair of $<1 \%$ in large series, with some centres achieving zero mortality (16-19).

\section{Valve repair rates and durability}

An added measure of confidence in the technology can be derived from the knowledge that benefits are accrued without compromising valve repair rates or the durability of mitral valve repair. In a regional Society of Thoracic Surgeons (STS) database analysis from 2011 to 2016, Hawkins et al. demonstrated a higher rate of repair in robotic procedures when compared with sternotomy despite similar rates of degenerative disease (20). Interestingly, in this study, which also matched patients to a minithoracotomy approach, repair techniques varied little between mini and robotic approaches, whereas sternotomy was associated with a greater number of leaflet resections. Large institutional series, such as from the Cleveland Clinic, have reported repair rates of $99.5 \%$ in almost 1,000 patients. Even early in robotic series, repair rates for degenerative pathology have been in excess of $98 \%(9,21,22)$.

Against this background, frequency of reinterventions for repair failures have reduced as centre experience increases and the learning curve is traversed. Chitwood et al. described an initial 7\% reoperation rate for repair failure in the first 100 cases which subsequently dropped to $4.5 \%$ in the following 200 cases (23). Murphy et al. also reported a fall in repeat mitral reinterventions over 5 years in 1,257 patients (16). During the first half of their study, reintervention rates were $6.8 \%$ dropping to $0.9 \%$ in the latter half and, in $91 \%$ of cases, it was possible to redo the procedure robotically. Reported 5 -year freedom from reoperations of $93.8 \%$ and $97.7 \%$, and 5- and 6-year freedom from $\geq 2+$ recurrent MR of $94.6 \%$ and $85 \%$ respectively provide evidence for durability of repair $(16,24)$.

\section{Operative durations}

Longer cardiopulmonary bypass (CPB) time, aortic cross clamp (XC) and total operative times for robotic mitral repair in comparison to both sternotomy and minithoracotomy are a frequent finding in all analyses. Although operative times decrease with increasing experience $(20,25,26)$, this is often offset by increasing operative complexity as confidence with the technique develops (27).

Techniques to reduce operative times have targeted endoscopic knot tying as one of the more labour intensive aspects of the procedure. Delegating this task to the bedside surgeon, rather than tying endoscopically with the robot, saves considerable time. A continuous running suture technique for annuloplasty band insertion, and pretied knots for atrial closure, has demonstrated a median 32-minute reduction in CPB and 19-minute reduction in cross clamp time (28). Some adaptations were less favourable, for example, the use of nitinol clips to secure annuloplasty bands. This resulted in a higher rate of ring dehiscence and was subsequently abandoned. The advent of automated titanium clip knot fasteners $\left(\mathrm{Cor}_{-K_{n o t}}{ }^{\circledR}\right.$, LSI Solutions, Victor, NY, USA) has been demonstrated to save over 20 minutes of ischemic time in both mini mitral and robotic surgery (29).

\section{Conversion to sternotomy}

Almost all successful robotic programmes have surgical teams highly experienced at mini mitral surgery, having performed several hundred of these before adopting robotic technology, and we would see this as a prerequisite to starting a robotic programme. Conversion to sternotomy can often be avoided by undocking the robot and extending the access port by $2 \mathrm{~cm}$ and completing the procedure as a mini mitral procedure thus still retaining a less invasive approach. Need for conversion from robotic access can be seen to reduce as experience is gained, with conversion occurring in 5-9.1\% during the early part of the learning curve, compared to $0.7-1.3 \%$ later on $(16,26,30)$. Conversion can occur for many reasons, such as instrument 
conflicts, bleeding, or concerns with aortic occlusion/ myocardial protection. Robotic system malfunctions are rare but have been reported $(16,23,26,31)$.

\section{Morbidity}

Most comparative series of robotic mitral surgery have demonstrated either a reduced or equal complication rate compared to sternotomy cases with a reduced length of ICU and hospital stay, and faster return to normal activities $(14,23,25,32,33)$. Wound infections are extremely rare with mini-thoracotomy approaches. One disadvantage, described in an STS database review by Gammie et al. exploring less invasive mitral surgery (robotic and mini mitral) versus sternotomy, was a higher rate of cerebrovascular accident (CVA), which has been attributed to retrograde femoral arterial perfusion. This reported an odds ratio of 1.96, suggesting nearly double the risk of CVA with less invasive techniques (34). However, on closer examination, a multitude of confounding factors obfuscated interpretation of Gammie's data including:

(I) Imprecise definitions of minimally invasive mitral valve surgery;

(II) The effect of the substantial learning curve;

(III) Retrospective comparisons of small historic cohorts with baseline differences and differing risk profiles for atherosclerosis;

(IV) Different methods of aortic occlusion and

(V) Lack of reporting of peripheral vascular disease (PVD) or aortic assessment in patient populations (35).

It is also important to note in Gammie's analysis that the median number of less invasive mitral cases per US centre per year was three. We have learned from Prof. Mohr's group in Leipzig that minimally invasive mitral surgery is an operation with a long learning curve (75-125 cases) with better results achieved in surgeons performing $>1$ case per week (36). Thus, at a rate of three cases per year, it would take only one surgeon in each unit a whole career to traverse the learning curve. Assessing results of a procedure performed by surgeons still in their learning curve will clearly bias the results. In all other analyses, including in patients older than 65 years, no significant difference has been demonstrated between stroke rates in robotic and sternotomy approaches $(25,26)$.

Length of ICU and hospital stay have consistently found in favour of robotic techniques, even when compared to a video-assisted approach. The hospital stay is consistently 1-2 days shorter with fewer ventilated hours and earlier
ICU discharge $(14,25,33,37)$. Murphy et al., in a series of 1,257 robotic mitral valve surgeries, reported a mean length of hospital stay of $4.9 \pm 4.4$ days with $37 \%$ patients being discharged within 4 days (16). This also translates into earlier return to paid employment on discharge (38).

The data for rates of blood transfusion and atrial fibrillation (AF) comparing robotic surgery to sternotomy is conflicting, with some reports suggesting a lower incidence of these (20) and others showing no difference $(22,26)$. Similarly, other reports have shown higher rates of these with robotic surgery than with the mini approach (25) whereas others have shown no difference (26).

\section{Disadvantages}

\section{Costs and the learning curve}

Without doubt the initial costs of developing a robotic programme are significant with the initial capital outlay followed by ongoing costs of the annual maintenance contract and instruments. Operative times are longer leading to fewer patients going through the operating suite on a daily basis offset by the increased volume of referrals that robotic surgery attracts. Data from the Cleveland Clinic shows that the learning curve is significant, with the greatest reduction in operative times occurring during the first 200 cases with only modest reductions beyond this $(19,39)$.

Paul et al. showed equivalent costs in 631 propensity matched pairs of patients from the National Inpatient Sample from 2008 to 2012 undergoing either robotic or sternotomy mitral valve repair (14). However, their data did not include the cost of the robotic system, maintenance and amortization. Coyan et al. did account for robotic capital depreciation and instrumentation costs, and showed no significant differences in total costs of robotic mitral operations compared to a propensity matched group of sternotomy operations $(\$ 27,662$ vs. $\$ 28,241, \mathrm{P}=0.27$, respectively) (33). Early direct costs were higher in the robotic group, balanced by higher late indirect costs in the sternotomy cohort, related to increased length of stay, transfusion requirements and readmission rates.

Using calculations taking into account purchase costs and maintenance as well as disposables, Mihaljevic et al. compared the economic benefits of robotic mitral repair versus alternative access via sternotomy, partial sternotomy and anterolateral thoracotomy using propensity matching (38). Income from return to paid employment as well as costs 
of postoperative care were considered. Overall costs for robotic procedures were between $14-16 \%$ greater than alternative surgical techniques. However, with cost projection it was possible to identify that in centres performing 55-100 cases per year, this would equilibrate over time with other techniques. In the majority of institutions, capital costs of the robot are spread across multiple surgical specialties and thus smaller volume robotic cardiac surgery programmes can still be economically viable (40). Regardless of how the capital cost is rationalized, it is unfair from an economic standpoint to consider this in a cost effectiveness analysis. The purchase of a robot is a sunk cost, meaning a cost that has already been incurred and cannot be recovered, in much the same way as is the cost of building a hybrid operating room to facilitate transcatheter aortic valve replacement (TAVR). As Halkos argues, the cost of the hybrid room is not incorporated into analyses when comparing TAVR to surgical aortic valve replacement (AVR), so why should robotic mitral valve repair be held to a different standard (40)?

Case volume is key to the success of a robotic mitral valve repair programme, not just for financial reasons but also the ability to successfully navigate the learning curve. Lessons from experienced centres highlight that good leadership and a dedicated team are vital and recommend a minimum number of 20 cases per year to maintain proficiency (41). As case selection is vital during the learning curve, only high volume centres have the caseload to do this in a temporally efficient manner. Detractors comment that there is a disparity in the frequency of robotic procedures being performed in centres that have the resources, given that few perform greater than 30 robotic cases per year (42).

\section{Lack of tactile feedback}

In our experience, visual clues such as tissue deformation provide adequate information. Reiley et al. demonstrated that visual force feedback primarily benefits novice robot-assisted surgeons with diminishing benefits among experienced surgeons (43).

\section{Technical considerations-tips and tricks to shorten the learning curve}

The techniques of robotic mitral valve repair have been extensively described elsewhere, so we would like to share the pearls and pitfalls that we have learned, and those which we feel are most important in the successful implementation of a robotic programme.

\section{Training and teamwork}

A team approach is vital to robotic surgery and this must be planned as conscientiously as the equipment from the inception of the programme. The console surgeon should be a high volume mini-mitral surgeon who has followed the Intuitive Surgical training pathway. Sitting at the console for the first time is not the time to be learning mitral valve repair or the nuances of managing $\mathrm{CPB}$ and myocardial protection from the right minithoracotomy approach. The anaesthetist should be skilled at 3D transoesophageal echocardiography and jugular drainage cannula insertion. Whether the bedside assistant is a second surgeon, fellow or surgical assistant needs to be decided early on, and the whole team needs to train together, both by visiting other established robotic programmes and performing wet labs and multiple dry runs. The surgeon who accepts the team for case observation should be the proctor for the first five cases. All the manoeuvres inside the heart should be practiced on latex models and/or pig hearts. With the surgeon at the console, the patient-side assistant and the scrub nurse need to be able to troubleshoot instrument conflicts and tie intra-corporeally. Both scrub nurse and circulating nurse should be familiar with mini mitral surgery. Communication must be clear given there is reliance from the console surgeon on the patient-side team. Wireless headsets improve the quality of communication between team members and reduce peak noise levels in the robotic operating room (44). Recognition of this difference in team dynamics means that in our institution there has been an emphasis on inclusion of all operating room staff in training with a low authority gradient, so all team members are empowered to speak up at any time.

\section{Patient and port-positioning}

The right chest is elevated by $30^{\circ}$ with a bolster under the right scapula and it is important that this is placed sufficiently caudad so that the head of the right humerus can fall posteriorly, helping to create room for the left arm port ( $3^{\text {rd }}$ intercostal space). A long port may be needed in large patients.

Make sure the centre post of the patient cart is level with the camera port - if too caudal, arms 3 and 4 both lie too flat and conflict externally. The access port and camera port both go in the same intercostal space, usually the $4^{\text {th }}$. Occasionally, it may be the third interspace in patients with a short chest cavity from cranial to caudal. We have found that 


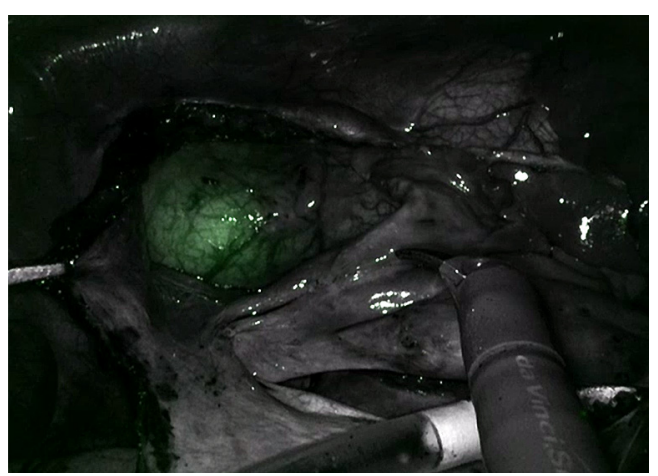

Figure 4 Indocyanine green fluorescing in the IntraClude in the mid ascending aorta.

a reliable indicator of the correct interspace is that overlying the right inferior pulmonary vein on the chest $\mathrm{X}$-ray.

The right arm port goes two interspaces caudal to the access port in the anterior axillary line. Left lateral rolling of the table will prevent conflict of the elbow of the right arm with the left iliac crest. The left atrial retractor port goes in the $4^{\text {th }}$ or $5^{\text {th }}$ interspace, medial to the midclavicular line.

\section{Cannulation}

Our preference is always to use an internal jugular drainage cannula in all patients as adequate venous drainage is never an issue. Remember that poor venous drainage will compromise right heart protection. Positioning the inferior vena cava (IVC) cannula into the superior vena cava (SVC) to act like a rod passing through the right atrium improves the valve exposure when the robotic left atrial retractor is deployed. A stiff venous cannula (e.g., Biomedicus, Medtronic, Dublin, Ireland) therefore has advantages over more flexible ones (e.g., Estech dual stage).

\section{CPB and myocardial protection}

Operative times will be prolonged during the learning curve, so systemic cooling to $28-30{ }^{\circ} \mathrm{C}$ is important for both myocardial protection and protection of the right lung to avoid unilateral pulmonary edema (45). Unilateral pulmonary edema is probably an ischemia-reperfusion injury of the right lung, occurs in $<1 \%$ of cases and is associated with a $33 \%$ mortality. Minimising the duration of single lung ventilation, maintenance of systemic pressure on $\mathrm{CPB} \geq 65 \mathrm{mmHg}$, minimising anaemia and active cooling on $\mathrm{CPB}$ are important preventative measures.
Myocardial protection with single dose cardioplegia (e.g., Custodiol ${ }^{\circledR}$ or del Nido) is helpful to avoid redosing. Additionally, crystalloid cardioplegia fits well with IntraClude use as the line pressures are lower during infusion than when blood cardioplegia is used. Beware, however, of repeated saline testing washing the cardioplegia out and compromising myocardial protection.

\section{Intraclude or transthoracic clamp}

There are, broadly speaking, two techniques for robotic mitral valve surgery based on the technique of aortic occlusion. The LEAR technique (Lateral Endoscopic Approach for Robotics) was developed by Dr. Douglas Murphy (Atlanta, USA) and is a port-based totally endoscopic approach using four 8-mm ports and one 20$\mathrm{mm}$ flexible access port (16). With a port-based approach, placing a cannula in the aortic root becomes challenging so an endoaortic balloon is used to occlude the aorta (IntraClude, Edwards Lifesciences, Irvine, CA, USA). This is the least invasive option but has the trade-off of adding an extra layer of complexity in the positioning and management of the IntraClude to ensure adequate aortic occlusion and myocardial protection is maintained. Deployment of the endoballoon is like flying a kite in the wind, its position being dependent on the pressure in the aorta balanced by the tension on its catheter. Therefore, bilateral radial arterial cannulae are required to detect distal migration which would occlude the origin of the innominate artery (e.g., if the systemic blood pressure falls). Constant vigilance is required.

One innovative development to assist with IntraClude placement is the use of an albumin and indocyanine green (ICG) solution to fill the balloon. This fluoresces with the firefly fluorescence imaging of the da Vinci system allowing real-time, image-guided placement of the IntraClude (Figure 4) (46). Disadvantages of the IntraClude include that it is single use and expensive $(£ 1,500)$. When this is added to the additional cost of the robotic procedure, where each of the five instruments has a limit of 10 uses (approx. $£ 200$ per use, thus an additional $£ 1,000$ per case), careful consideration needs to be given to the cost: benefit ratio in healthcare systems with constrained resources. There is also a learning curve for the IntraClude, and it is not wise to allow the learning curve of robotic surgery to overlap that of the IntraClude.

The alternative technique popularised by Dr. Randolph Chitwood (Greenville, NC, USA) uses a 4-cm 


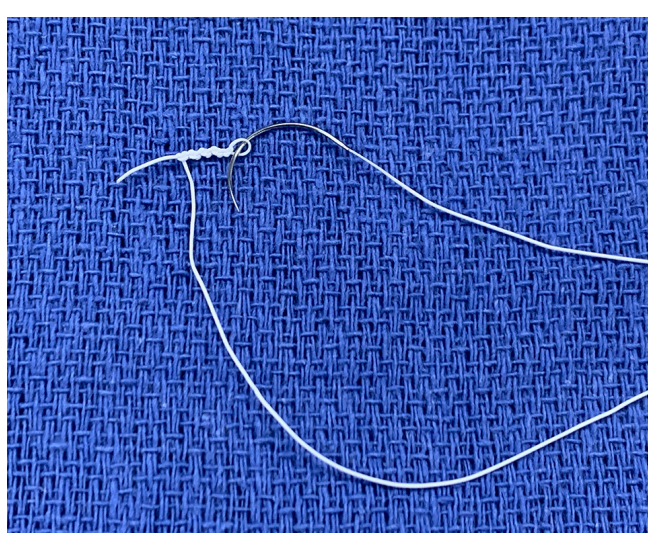

Figure 5 Pre-knotted suture, made by knotting a CV4 GoreTex suture over a nerve hook.

minithoracotomy, through which the 3D scope is placed, and three 8-mm ports. A transthoracic clamp (Chitwood clamp) is used to occlude the aorta. This has the advantage that it does not migrate, provides reliable aortic occlusion and, as it is reusable, is more cost effective. Smaller femoral cannulae can be used as there is no need to accommodate the catheter of the IntraClude, arterial line pressures are lower and bilateral femoral cannulation is consequently rarely needed. This provides a significant cost saving and importantly makes the overall procedure less complex but does have some disadvantages. Firstly, a minithoracotomy is needed rather than a truly port-based approach; secondly, there is the potential for conflict between the clamp and the left robotic arm and thirdly, it necessitates a $2^{\text {nd }}$ bypass run to decannulate and control the root of the aorta, which can occasionally lead to troublesome bleeding.

\section{Repair technique}

If the valve repair looks more complex than initially anticipated, undock the robot, return to the tableside, extend the incision by $1-2 \mathrm{~cm}$, and proceed as a mini mitral. Never compromise on quality of the repair. Using the tableside assistant to tie the knots saves time; Cor-Knot ${ }^{\circledR}$ also saves time. Most surgeons use flexible bands rather than rings with robotics, but it is perfectly possible to place a semi-rigid band or ring with the robot. Use pre-knotted sutures for left atrial closure to save further time (Figure 5).

\section{Patient selection}

The surgical approach (robot vs. mini vs. sternotomy) should be tailored both to the patient and the experience of the surgical team using the following rules:

(I) Safety must never be compromised;

(II) Repairability of the valve should never be compromised;

(III) These are both achieved in the least invasive way possible.

For the first five cases, the ideal patients are slim males with large femoral vessels and isolated posterior leaflet prolapse with some excess tissue. Exclusion criteria vary with experience and are more stringent at the start of the programme. Some consider pre-operative aortoiliac contrast-enhanced CT important for operative planning. This assesses for atherosclerotic burden with some evidence that it is associated with a reduced risk of stroke $(35,47)$ but also identifies arterial/venous anatomy, as well as obliquity of the ribs which has implications for port placement. The Cleveland Clinic group have documented a thorough list of exclusion criteria as follows: aortic regurgitation, mitral annular calcification, reoperation, left ventricular (LV) dysfunction/dilatation, severe pulmonary hypertension, aortoiliac atherosclerosis, femoral artery diameter $<7 \mathrm{~mm}$, and pectus excavatum (19).

However, it must not be forgotten that the patients who are going to gain the most benefit from less invasive techniques are the highest risk patients, those who tolerate the conventional surgical trauma least well. An extensive list of exclusion criteria will deny many patients the benefits of robotic surgery. As experience with the robotic platform increases, many of these become relative, e.g., axillary cannulation can be used when the thoracic or abdominal aorta has grade $\mathrm{V}$ atheroma or the femoral arteries are small, and reoperations are technically easier and safer through the right chest after prior sternotomy.

\section{Conclusions}

Totally endoscopic robotic mitral valve repair, performed in high-volume centres by high-volume surgeons, represents the least invasive form of surgical therapy for mitral valve disease. This leads to a rapid return to normal activities, with proven mid-term durability and prognostic advantage. When one weighs this against the uncertain durability and residual MR associated with transcatheter repairs, it becomes clear that robotic techniques will be a major hurdle lying in the pathway of the inexorable advance of transcatheter techniques. As experience grows with robotic techniques and more cardiac surgeons become proficient 
with this innovative technology, the volume of robotic cardiac procedures around the world will increase helped by the introduction of new robotic systems and patient demand. Well informed patients will increasingly seek out the opportunity of robotic valve reconstruction in reference centres in the hands of a few highly experienced robotic surgeons.

\section{Acknowledgments}

Funding: None.

\section{Footnote}

Provenance and Peer Review: This article was commissioned by the Guest Editors (Jason Ali and Yasir Abu-Omar) for the series "Minimally Invasive Cardiac Surgery" published in Fournal of Thoracic Disease. The article has undergone external peer review.

Peer Review File: Available at http://dx.doi.org/10.21037/jtd20-1790

Conflicts of Interest: All authors have completed the ICMJE uniform disclosure form (available at http://dx.doi. org/10.21037/jtd-20-1790). The series "Minimally Invasive Cardiac Surgery" was commissioned by the editorial office without any funding or sponsorship. The authors have no other conflicts of interest to declare.

Ethical Statement: The authors are accountable for all aspects of the work in ensuring that questions related to the accuracy or integrity of any part of the work are appropriately investigated and resolved.

Open Access Statement: This is an Open Access article distributed in accordance with the Creative Commons Attribution-NonCommercial-NoDerivs 4.0 International License (CC BY-NC-ND 4.0), which permits the noncommercial replication and distribution of the article with the strict proviso that no changes or edits are made and the original work is properly cited (including links to both the formal publication through the relevant DOI and the license). See: https://creativecommons.org/licenses/by-nc-nd/4.0/.

\section{References}

1. Beckmann A, Meyer R, Lewandowski J, et al. German
Heart Surgery Report 2018: The Annual Updated Registry of the German Society for Thoracic and Cardiovascular Surgery. Thorac Cardiovasc Surg 2019;67:331-44.

2. Cheng DC, Martin J, Lal A, et al. Minimally invasive versus conventional open mitral valve surgery: a metaanalysis and systematic review. Innovations (Phila) 2011;6:84-103.

3. Cao C, Gupta S, Chandrakumar D, et al. A meta-analysis of minimally invasive versus conventional mitral valve repair for patients with degenerative mitral disease. Ann Cardiothorac Surg 2013;2:693-703.

4. Modi P, Hassan A, Chitwood WR Jr. Minimally invasive mitral valve surgery: a systematic review and meta-analysis. Eur J Cardiothorac Surg 2008;34:943-52.

5. Sundermann SH, Sromicki J, Rodriguez Cetina Biefer H, et al. Mitral valve surgery: right lateral minithoracotomy or sternotomy? A systematic review and meta-analysis. J Thorac Cardiovasc Surg 2014;148:1989-1995.e4.

6. Glauber M, Miceli A, Canarutto D, et al. Early and longterm outcomes of minimally invasive mitral valve surgery through right minithoracotomy: a 10-year experience in 1604 patients. J Cardiothorac Surg 2015;10:181.

7. Carpentier A, Loulmet D, Aupecle B, et al. Computer assisted open heart surgery. First case operated on with success. C R Acad Sci III 1998;321:437-42.

8. Mohr FW, Falk V, Diegeler A, et al. Computer-enhanced coronary artery bypass surgery. J Thorac Cardiovasc Surg 1999;117:1212-4.

9. Chitwood WR Jr, Nifong LW, Elbeery JE, et al. Robotic mitral valve repair: trapezoidal resection and prosthetic annuloplasty with the da vinci surgical system. J Thorac Cardiovasc Surg 2000;120:1171-2.

10. Grossi EA, Lapietra A, Applebaum RM, et al. Case report of robotic instrument-enhanced mitral valve surgery. J Thorac Cardiovasc Surg 2000;120:1169-71.

11. Nifong LW, Chu VF, Bailey BM, et al. Robotic mitral valve repair: experience with the da Vinci system. Ann Thorac Surg 2003;75:438-42; discussion 443.

12. Nifong LW, Chitwood WR, Pappas PS, et al. Robotic mitral valve surgery: a United States multicenter trial. J Thorac Cardiovasc Surg 2005;129:1395-404.

13. Pettinari M, Navarra E, Noirhomme P, et al. The state of robotic cardiac surgery in Europe. Ann Cardiothorac Surg 2017;6:1-8.

14. Paul S, Isaacs AJ, Jalbert J, et al. A population-based analysis of robotic-assisted mitral valve repair. Ann Thorac Surg 2015;99:1546-53.

15. Cao C, Wolfenden H, Liou K, et al. A meta-analysis of 
robotic vs. conventional mitral valve surgery. Annals of cardiothoracic surgery 2015;4:305-14.

16. Murphy DA, Moss E, Binongo J, et al. The Expanding Role of Endoscopic Robotics in Mitral Valve Surgery: 1,257 Consecutive Procedures. Ann Thorac Surg 2015;100:1675-81; discussion 1681-2.

17. Nifong LW, Rodriguez E, Chitwood WR Jr. 540 consecutive robotic mitral valve repairs including concomitant atrial fibrillation cryoablation. Ann Thorac Surg 2012;94:38-42; discussion 43.

18. Tarui T, Ishikawa N, Horikawa T, et al. First Major Clinical Outcomes of Totally Endoscopic Robotic Mitral Valve Repair in Japan- A Single-Center Experience. Circ J 2019;83:1668-73.

19. Gillinov AM, Mihaljevic T, Javadikasgari H, et al. Early results of robotically assisted mitral valve surgery: Analysis of the first 1000 cases. J Thorac Cardiovasc Surg 2018;155:82-91.e2.

20. Hawkins RB, Mehaffey JH, Mullen MG, et al. A propensity matched analysis of robotic, minimally invasive, and conventional mitral valve surgery. Heart 2018;104:1970-5.

21. Murphy DA, Miller JS, Langford DA, et al. Endoscopic robotic mitral valve surgery. J Thorac Cardiovasc Surg 2006;132:776-81.

22. Suri RM, Burkhart HM, Daly RC, et al. Robotic mitral valve repair for all prolapse subsets using techniques identical to open valvuloplasty: establishing the benchmark against which percutaneous interventions should be judged. J Thorac Cardiovasc Surg 2011;142:970-9.

23. Chitwood WR Jr, Rodriguez E, Chu MW, et al. Robotic mitral valve repairs in 300 patients: a single-center experience. J Thorac Cardiovasc Surg 2008;136:436-41.

24. Suri RM, Taggarse A, Burkhart HM, et al. Robotic Mitral Valve Repair for Simple and Complex Degenerative Disease: Midterm Clinical and Echocardiographic Quality Outcomes. Circulation 2015;132:1961-8.

25. Wang A, Brennan JM, Zhang S, et al. Robotic Mitral Valve Repair in Older Individuals: An Analysis of The Society of Thoracic Surgeons Database. Ann Thorac Surg 2018;106:1388-93.

26. Mihaljevic T, Jarrett CM, Gillinov AM, et al. Robotic repair of posterior mitral valve prolapse versus conventional approaches: Potential realized. J Thorac Cardiovasc Surg 2011;141:72-80.e4.

27. Charland PJ, Robbins T, Rodriguez E, et al. Learning curve analysis of mitral valve repair using telemanipulative technology. J Thorac Cardiovasc Surg 2011;142:404-10.
28. Mihaljevic T, Jarrett CM, Gillinov AM, et al. A novel running annuloplasty suture technique for robotically assisted mitral valve repair. J Thorac Cardiovasc Surg 2010;139:1343-4.

29. Perin G, Shaw M, Pingle V, et al. Use of an automated knot fastener shortens operative times in minimally invasive mitral valve repair. Ann R Coll Surg Engl 2019;101:522-8.

30. Javadikasgari H, Suri RM, Tappuni B, et al. Robotic mitral valve repair for degenerative posterior leaflet prolapse. Ann Cardiothorac Surg 2017;6:27-32.

31. Cheng W, Fontana GP, De Robertis MA, et al. Is robotic mitral valve repair a reproducible approach? J Thorac Cardiovasc Surg 2010;139:628-33.

32. Folliguet T, Vanhuyse F, Constantino X, et al. Mitral valve repair robotic versus sternotomy. Eur J Cardiothorac Surg 2006;29:362-6.

33. Coyan G, Wei LM, Althouse A, et al. Robotic mitral valve operations by experienced surgeons are costneutral and durable at 1 year. J Thorac Cardiovasc Surg 2018;156:1040-7.

34. Gammie JS, Zhao Y, Peterson ED, et al. Less-Invasive Mitral Valve Operations: Trends and Outcomes From The Society of Thoracic Surgeons Adult Cardiac Surgery Database. The Annals of Thoracic Surgery 2010;90:1401-10.e1.

35. Modi P, Chitwood WR Jr. Retrograde femoral arterial perfusion and stroke risk during minimally invasive mitral valve surgery: is there cause for concern? Ann Cardiothorac Surg 2013;2:E1.

36. Holzhey DM, Seeburger J, Misfeld M, et al. Learning minimally invasive mitral valve surgery: a cumulative sum sequential probability analysis of 3895 operations from a single high-volume center. Circulation 2013;128:483-91.

37. Kam JK, Cooray SD, Kam JK, et al. A cost-analysis study of robotic versus conventional mitral valve repair. Heart Lung Circ 2010;19:413-8.

38. Mihaljevic T, Koprivanac M, Kelava M, et al. Value of robotically assisted surgery for mitral valve disease. JAMA Surg 2014;149:679-86.

39. Goodman A, Koprivanac M, Kelava M, et al. Robotic Mitral Valve Repair: The Learning Curve. Innovations (Phila) 2017;12:390-7.

40. Moss E, Halkos ME. Cost effectiveness of robotic mitral valve surgery. Ann Cardiothorac Surg 2017;6:33-7.

41. Rodriguez E, Nifong LW, Bonatti J, et al. Pathway for surgeons and programs to establish and maintain a successful robot-assisted adult cardiac surgery program. J Thorac Cardiovasc Surg 2016;152:9-13. 
42. Robicsek F. Robotic cardiac surgery: time told! J Thorac Cardiovasc Surg 2008;135:243-6.

43. Reiley CE, Akinbiyi T, Burschka D, et al. Effects of visual force feedback on robot-assisted surgical task performance. J Thorac Cardiovasc Surg 2008;135:196-202.

44. Tsafrir Z, Janosek-Albright K, Aoun J, et al. The impact of a wireless audio system on communication in roboticassisted laparoscopic surgery: A prospective controlled trial. PLoS One 2020;15:e0220214.

45. Moss E, Halkos ME, Binongo JN, et al. Prevention of Unilateral Pulmonary Edema Complicating Robotic

Cite this article as: Toolan C, Palmer K, Al-Rawi O, Ridgway T, Modi P. Robotic mitral valve surgery: a review and tips for safely negotiating the learning curve. J Thorac Dis 2021;13(3):1971-1981. doi: 10.21037/jtd-20-1790
Mitral Valve Operations. Ann Thorac Surg 2017;103:98104.

46. Yaffee DW, Loulmet DF, Fakiha AG, et al. Fluorescenceguided placement of an endoaortic balloon occlusion device for totally endoscopic robotic mitral valve repair. J Thorac Cardiovasc Surg 2015;149:1456-8.

47. Leonard JR, Henry M, Rahouma M, et al. Systematic preoperative CT scan is associated with reduced risk of stroke in minimally invasive mitral valve surgery: A metaanalysis. Int J Cardiol 2019;278:300-6. 